\title{
Bio-based macroporous polymer nanocomposites made by mechanical frothing of acrylated and epoxidised soybean oil
}

\author{
Koon-Yang Lee, Ling Ching Wong, Jonny J. Blaker, John M. Hodgkinson and Alexander
}

\author{
Bismarck ${ }^{*}$ \\ Polymers and Composites Engineering (PaCE) group \\ Department of Chemical Engineering \\ Imperial College London \\ South Kensington Campus \\ SW7 2AZ London UK
}

Keywords: bacterial cellulose; foams; macroporous polymers; mechanical properties; nanocomposites

\begin{abstract}
Mechanical frothing is one of the most commonly used methods to create gas-liquid foams. Until recently, the polymerisation of mechanically frothed gas-liquid foams was limited to quasi two-dimensional polymer structures, such as films. In this study we show that threedimensional bio-based polymer foams can be created by microwave curing of gas-soybean oil foams created by mechanical frothing using peroxide as the radical initiator. It was found that the introduction of air during the mechanical frothing was necessary to create the three-dimensional polymer foams. The potential of using bacterial cellulose nanofibrils (BC) simultaneously as stabilisers by obstructing the flow of liquid from the lamella region for these gas-soybean oil foams and nano-filler in the polymer foam is also demonstrated. It was found that the stability of the gas-soybean oil foam templates and the mechanical properties of the polymer nanocomposite foams are enhanced upon the addition of $\mathrm{BC}$ foams.
\end{abstract}

\footnotetext{
* Corresponding author. Tel.: +44 (0)20 7494 5578; fax: +44 (0)20 7594 5638;

Email address: a.bismarck@imperial.ac.uk
} 


\section{Introduction}

Polymer foams, which represent a group of lightweight materials, were a $£ 7.5$ billion industry in the year 2010 and are expected to reach $£ 8.6$ billion by the year $2015 .{ }^{1}$ These very porous and low density foams makes them attractive materials for both science and engineering applications. ${ }^{2}$ Generally, polymer foams can be classified into rigid or flexible foams, open- or closed-cell foams. Open-cell foams can be used as scaffolds for tissue engineering ${ }^{3-5}$ or catalyst supports $^{6}$ whereas closed-cell foams have found application in sandwich structures ${ }^{7}$ and thermal insulation. ${ }^{8}$ Generally, the interconnected nature of open-cell foams provides better permeability while closed-cell foams offer low or zero permeability, which results in better insulating properties. ${ }^{9}$

Polymer foams can be produced in various ways; by using chemical or physical blowing agents, ${ }^{10-12}$ thermally induced phase separation (TIPS), ${ }^{13,}{ }^{14}$ sintering of particles/microspheres ${ }^{15}$, ${ }^{16}$ or polymerising the continuous phase of suitable emulsion templates. ${ }^{2,}{ }^{17}$ A novel technique to produce foams has been reported by Murakami and Bismarck. ${ }^{18}$ The authors utilised oligomeric tetrafluoroethylene (OTFE) particles to stabilise air bubbles in monomers and UV-polymerised this foam to produce macroporous closed cell polymers. A similar technique was also used to produce macroporous ceramics. ${ }^{19} \mathrm{~A}$ wet foam was produced by mechanically frothing a suspension of hydrophobic alumina powder. The alumina powder serves as foam stabilisers. After a drying step to remove the water followed by sintering of the alumina, Gonzenbach et al. ${ }^{19}$ were able to produce macroporous ceramics with porosities up to $88 \%$. However, the polymerisation of mechanical frothed organic gas-monomer foams remain under studied. Marlin et al. ${ }^{20}$ first studied macroporous polymers produced from mechanically frothed air-urethane 
foams. The authors mechanically frothed a mixture of isocyanate, polyols, surfactants and catalyst with air, followed by thermal polymerisation of the monomer to produce polymeric foams. However, the authors only managed to produce two-dimensional (2D) polymer foams of 6 $\mathrm{mm}$ in thickness. Greer and Wilkes ${ }^{21}$ mechanically frothed a highly viscous oligomer solution, polymerisation was initiated using a $175 \mathrm{keV}$ electron beam to produce $2 \mathrm{D}$ thin $(0.5 \mathrm{~mm}$ thick $)$ polymer foams. They also used the same technique to produce polymeric foams from surfactant stabilised low viscosity monomers. However, the use of a high-energy electron beam reduces the commercial value of this technology.

In this study, a soybean oil-derived renewable monomer was mechanically frothed to create foams. The foam was polymerised using microwave irradiation to produce macroporous threedimensional (3D) polymers. We also produced macroporous polymer nanocomposites by dispersing bacterial cellulose nanofibrils $(\mathrm{BC})$ in the monomer phase. $\mathrm{BC}$ is produced by the Acetobacter species $^{22}$ and has the advantage of being free of wax, lignin, pectin and hemicellulose. It is highly crystalline in nature, with a degree of crystallinity of approximately $90 \%{ }^{23} \mathrm{BC}$ inherently has nanometre dimensions (24 - $86 \mathrm{~nm}$ in diameter, see Figure 1$)$, and unlike plant-based sources of cellulose, does not require nanofibrillation. ${ }^{24}$ Hsieh et al. ${ }^{25}$ predicted that BC possesses a Young's modulus of $114 \mathrm{GPa}$. These properties make BC an attractive nanofiller to reinforce fine structures, such as fibres, foams ${ }^{26}$ and the matrix of composite materials. ${ }^{27,28} \mathrm{Wu}$ et al. ${ }^{29}$ used chemical blowing agent to produce soybean oil-derived macroporous polymers but styrene and methyl methacrylate were used as the solvents to dilute the soybean oil derived monomer and surfactants were also used to stabilise the foam during polymerisation. Bonnaillie et al. ${ }^{30}$ pressurised $\mathrm{CO}_{2}$ to 60 bar and used it as the physical blowing agent to produce soybean oil-derived macroporous polymers. Our current study focuses on a 
solvent- and surfactant-free process that operates at atmospheric condition to produce polymer foams. By reinforcing soybean oil derived polymer foams with $\mathrm{BC}$, a new type of green macroporous polymer nanocomposites can be manufactured via simple mechanical frothing of monomer.

\section{Results and discussion}

\section{Stability indices of the liquid foam}

The stability of gas-AESO liquid foam templates is very important for the resulting polymer foams. The stability index of gas-AESO liquid foams was determined by tracking the movement of the air-monomer interface due to creaming visually. Photographs of the mechanically frothed gas-AESO and gas-AESO-BC liquid foams are shown in Figure 2. The ability of the gas-AESO and gas-AESO-BC liquid foams to flow under gravity is shown in Figure 3. It can be seen from Figure 3 that AESO 1 flows easier than AESO 2 and 3. This is due to the viscosifying effect of $\mathrm{BC}$ in AESO. $\mathrm{BC}$ is known as a thickening agent, stabiliser and texture modifier. ${ }^{31}$ The stability of the liquid foams as a function of time is shown in Figure 4. The neat liquid AESO foams without BC (AESO 1) destabilised rapidly compared to the liquid AESO foams containing 0.5 wt.- $\%$ and 1 wt.-\% of BC (AESO 2 and 3 ). In fact, AESO 2 and AESO 3 showed insignificant changes in terms of the liquid foam height even 70 days after the foams were prepared. In contrast to AESO $\mathbf{2}$ and $\mathbf{3}$, the liquid foam height of AESO 1 reduced to half of its original height just 5 days after preparation and was fully phase separated after 70 days.

The stability of liquid foams is largely governed by the dynamics of the thin interfacial films, which formed between air bubbles approaching each other. Two main mechanisms are involved 
in liquid foam destabilisation; gravitational and capillary drainage. ${ }^{32}$ The liquid foam will first undergo gravitational drainage, whereby two adjacent bubbles approach each other, resulting in the reduction of foam lamella thickness. The drained liquid will move to the edge of the planar foam lamella, known as the Plateau border. A second mechanism known as capillary drainage will become dominant when the pressure in the foam lamella is larger than the pressure in the Plateau border. As the monomer drains from the foam lamella to the Plateau border, due to pressure differences, the air bubbles will approach each other resulting in bubble coalescence. ${ }^{33}$ The foam AESO 1, which does not contain $\mathrm{BC}$, exhibited rapid destabilisation due to the expected fast kinetics of gravitational drainage, followed by capillary drainage, which ultimately resulted in the full phase separation of the foam by 70 days. When the monomer phase contains BC (AESO 2 and AESO 3), the kinetics of destabilisation were significantly reduced. It has been proposed that nano-particles in the liquid phase of foams will aggregate in the Plateau border, obstructing the flow of the liquid from the lamella. ${ }^{34}$ Ultimately, this liquid flow obstruction hinders the coalescence of bubbles in foams.

\section{Structure and morphology of the macroporous polymer nanocomposites}

SEM images showing the internal structure and morphology of the polymerised AESO macroporous polymers (polyAESO) are shown in Figure 5. It can be seen from the SEM images that the pores are randomly oriented with pore shapes that are spherical, semi-ellipsoidal or highly irregular, both from the top and side views of the materials. Pore throats can be seen in the pores, indicating that the pores are interconnected. However, the pore size is highly non-uniform throughout the samples as seen in Figure 5. The pores in the macroporous polymer are formed by the polymerisation of the liquid monomer foam templates produced by mechanical frothing, with some contribution from the additional $\mathrm{CO}_{2}$ released by the thermal decomposition of the 
initiators (one mole of initiator produces two moles of $\mathrm{CO}_{2}$ ). With increasing $\mathrm{BC}$ loading, the monomer phase became more viscous (Figure 3) and the expansion of the bubbles in the gasmonomer liquid foams could not reach its equilibrium state within the time frame of the polymerisation of AESO. This quasi-equilibrium state of the bubbles results in the randomly orientated ellipsoidal pores (polyAESO 1 and 2). Increasing the BC concentration to 1 wt.-\% (polyAESO 3) increases the viscosity of the continuous phase even further and results in polymer foam structures with very irregular and ill-defined pores.

\section{Porosity of the macroporous polymer nanocomposites}

Porosity is one of the important factors that govern the physical properties of macroporous polymers. Both the measured envelope and matrix densities along with the calculated porosity of the macroporous polymer and its nanocomposites are tabulated in Table 1 . It can be seen that the envelope density increased from $0.44 \mathrm{~g} \mathrm{~cm}^{-3}$ to $0.58 \mathrm{~g} \mathrm{~cm}^{-3}$ and the porosity of the polyAESO decreases from $59 \%$ to $45 \%$ with increasing $\mathrm{BC}$ content. The introduction of $\mathrm{BC}$ into the monomer phase resulted in difficulties to mechanically froth the liquid at constant input of frothing energy. Even though the thermal degradation of the initiator could potentially contribute to the porosity (approximately $130 \mathrm{~cm}^{3}$ of $\mathrm{CO}_{2}$ produced per $100 \mathrm{~mL}$ of AESO used), the images shown in Figure 6 shows otherwise. Polymerising AESO containing 1 wt.-\% of initiator could potentially result in a theoretical porosity of $56 \%$. However, the microwave irradiation also increased the temperature of the monomer to approximately $150^{\circ} \mathrm{C}^{\dagger}$. At this temperature, the viscosity of the monomer phase is low enough for the $\mathrm{CO}_{2}$ produced to rise to the air-monomer interface and escape from the monomer phase before it gels and cured. Therefore, non-frothed

\footnotetext{
$\dagger$ This temperature was obtained by measuring the temperature of the microwave-irradiated monomer without thermal initiator immediately after irradiation.
} 
AESO did not polymerise into porous polymers (see Figure 6). By frothing the monomer phase, air bubbles are introduced. It is hypothesised that the $\mathrm{CO}_{2}$ produced can escape from the monomer phase to the air-monomer interface at the top of the cylindrical vessel or into the air bubbles formed during mechanical frothing. The latter resulted in the expansion of the air bubbles during the polymerisation of the monomer. This might also explain why ellipsoidal pores are observed in polyAESO. The ellipsoidal pores could also be a result of buoyancy induced creaming.

\section{TGA of the macroporous polymer nanocomposites}

The thermal degradation behaviour of the macroporous polymer and its nanocomposites is shown in Figure 7. It can be seen that all the samples undergo single step degradation in nitrogen atmosphere. Random polymer chain scission occurred during the degradation of polyAESO. ${ }^{35}$ The introduction of BC into the sample did not alter the degradation behaviour of polyAESO. This might be due to the low $\mathrm{BC}$ content in the sample. The onset degradation temperature determined from TGA analysis of the foams was found to be $380^{\circ} \mathrm{C}$ for all samples. In addition to this, the residual carbon content for polyAESO 1 was found to be $0.98 \mathrm{wt} .-\%$ and approximately 2 wt.- $\%$ for both polyAESO 2 and 3 . The increase in the residual carbon content of polyAESO 2 and 3 compared to polyAESO 1 can be explained by the carbonisation of $\mathrm{BC}$ in the nanocomposites.

\section{Compression properties of the macroporous polymer nanocomposites}

The mechanical properties of the macroporous polymer nanocomposites determine their potential applications. The compressive modulus and strength, along with the specific compressive modulus and strength (absolute compressive properties divided by the envelope density of the 
material) of the macroporous polymer and its nanocomposites are summarised in Table 2 and characteristic load-displacement curves of the linear elastic region are shown in Figure 8. It should be noted that the polyAESO with different BC loadings possess different porosities and, therefore, we compare only the specific compressive properties of the polyAESO. By adding 0.5 wt.- $\%$ of BC (polyAESO 2), the specific modulus increased from $253 \mathrm{MPa} \mathrm{kg}^{-1} \mathrm{~m}^{3}$ to 339 $\mathrm{MPa} \mathrm{kg} \mathrm{km}^{3}$. Even at such low nano-filler loading fraction, a 35\% increase in the specific compression modulus was observed. This increase in stiffness of the foam can be attributed to the stiffness of BC, which has been estimated to possess a Young's modulus of $114 \mathrm{GPa}^{25}$ However, when the nano-filler content was increased to $1 \mathrm{wt} .-\%$ BC (polyAESO 3), the specific modulus decreased by $60 \%$ to $90.2 \mathrm{MPa} \mathrm{kg}^{-1} \mathrm{~m}^{3}$ when compared to polyAESO 1 . This decrease in the compressive modulus of polyAESO 3 is thought to be due the ill-defined pore structure due to the inclusion of $\mathrm{BC}$ into the macroporous polymer (see Figure 5). The specific compressive strength of the polyAESO showed a different trend compared to the compressive modulus. It was observed that the compressive strength of the polyAESO decreased with increasing BC content (Table 2). The compressive strength of the polymer nanocomposite foams decreased by as much as $60 \%$ from $777 \mathrm{kPa} \mathrm{kg}^{-1} \mathrm{~m}^{3}$ to $315 \mathrm{kPa} \mathrm{kg}^{-1} \mathrm{~m}^{3}$ when the $\mathrm{BC}$ content was increased to $1 \mathrm{wt} .-\%$. It is proposed that the poor specific strength of the nanocomposites is due to the poor compatibility and hence, poor stress transfer between $\mathrm{BC}$ and the polymerised AESO.

The presence of unreacted AESO in the macroporous polymers could also affect the mechanical properties by the plasticising action of the monomer. ${ }^{36}$ It can be postulated that any unreacted monomer present only at the pore walls, where the monomer is exposed to oxygen during the polymerisation process. The oxygen-exposed surface will remain "tacky" as oxygen inhibits the surface polymerisation. ${ }^{37}$ However, the macroporous polymers were washed with ethanol to 
remove any unreacted monomer prior to mechanical testing. In addition to this, the mechanical properties of porous materials are governed predominantly by cellular morphology and the properties of the base polymer. ${ }^{38}$ Therefore, any remaining unreacted AESO will not affect the mechanical properties measured in this study.

\section{Conclusions}

Studies on the mechanical frothing of liquid monomers to produce non-aqueous foam templates followed by their polymerisation to produce polymeric foams had been conducted in the 1970 s. However, this technique was limited to the production of $2 \mathrm{D}$ foams, which might be due to the instability of the air-monomer foam. In this study however, we succeeded in producing macroporous polymers through microwave heating of mechanically frothed gas-AESO liquid foams containing lauroyl peroxide as thermal initiator due to the high viscosity of the monomer phase and the obstruction of the flow into the Plateau border by BC. Through this route, we were able to produce 3D macroporous polymers. The resulting bio-based macroporous polymers possessed a porosity of approximately $60 \%$ but it was found that the stability of the gas-AESO liquid foam template was poor. This liquid foam destabilises within 7 days of preparation at room temperature. In order to enhance the stability of the gas-AESO liquid foams and the mechanical properties of the macroporous polymers, BC was added as a nano-filler to produce macroporous polymer nanocomposites. With the introduction of $\mathrm{BC}$, the stability of the liquid AESO foams was significantly enhanced. No phase separation (e.g. creaming) was observed 70 days after the preparation of the liquid foams. This was thought to be due to the obstruction of the Plateau border in the presence of $\mathrm{BC}$ during capillary drainage of the monomer liquid foams. The incorporation of $0.5 \mathrm{wt} .-\mathrm{\%} \mathrm{BC}$ into the polymeric foams resulted in a significant increase of the 
specific compression modulus when compared to the neat polymer foams. This was attributed to the reinforcing effect of the highly crystalline and stiff $\mathrm{BC}$. However, a further increase of $\mathrm{BC}$ to 1 wt.- $\%$ resulted in a decrease of the specific compression modulus when compared to the neat polymeric foams. This is thought to be due to the ill-defined cell structure of the macroporous polymer nanocomposites at $1 \mathrm{wt} .-\% \mathrm{BC}$ loading. It was hypothesised that the poor compatibility between $\mathrm{BC}$ and polymerised AESO has resulted in the decrease of the compressive strength of the polyAESO with increasing BC content.

\section{Experimental}

\section{Materials}

Epoxidised and acrylated soybean oil, AESO (Aldrich, density $=1.04 \mathrm{~g} \mathrm{~cm}^{-3}$, inhibited with 8500 ppm monomethyl ether hydroquinone), was purchased from Sigma-Aldrich and used as the monomer in this study. Lauroyl peroxide, also known as dodecanoyl peroxide (Alfa Aesar, purity $\geq 97 \%$ ), and ethanol (GPR, purity $\geq 99.7 \%$ ) were purchased from VWR International UK. Lauroyl peroxide was selected as the thermal initiator for this study because of its low initiation temperature $\left(10 \mathrm{~h}\right.$ half-life at $\left.65^{\circ} \mathrm{C}\right)$. De-ionised water was used throughout this study and was obtained by passing water through a reverse osmosis water filtration unit (Triple Red Laboratory Technology, Bucks, UK). BC nanofibrils were extracted from commercially available nata-decoco (CHAOKOH coconut gel in syrup, Ampol Food Processing Ltd, Nakorn Pathom, Thailand) following previously described work ${ }^{26,39,40}$ and used in its freeze-dried form in this work.

\section{Macroporous polymer nanocomposites preparation}


Polymer foams of neat AESO (polyAESO 1) were prepared by polymerising the gas-AESO liquid foams (AESO 1) using lauroyl peroxide as the radical initiator. Firstly, 1 wt.-\% (2.5 mol.$\%$ ) of lauroyl peroxide (relative to the monomer phase) was mixed with AESO and air was introduced into the monomer by using a hand mixer operating at its maximum power output (100 W) for 5 min. The resulting gas-AESO liquid foam (AESO 1) was shaped into cylindrical glass vials (25 $\mathrm{mm}$ in diameter and $60 \mathrm{~mm}$ in height) using spatula and polymerised for 2 min using microwave irradiation, operating at a frequency and power output of $2.45 \mathrm{GHz}$ and $700 \mathrm{~W}$, respectively. After polymerisation of the gas-AESO foams, the samples were left to cool to room temperature before washing them with ethanol to remove the unreacted monomer, followed by de-ionised water. The polymeric foams were then dried at $40^{\circ} \mathrm{C}$ in an air oven overnight. GasAESO liquid foams with 0.5 wt.-\% BC (AESO 2) and 1 wt.-\% BC (AESO 3) were prepared by mixing $\mathrm{BC}$ and 1 wt.- $\%$ of lauroyl peroxide (relative to AESO) followed by the introduction of air into the $\mathrm{BC}$-monomer dispersion using the hand mixer as previously described. The gasAESO-BC liquid foams (AESO 2 and 3) were then polymerised and washed following the previously described methods. The macroporous polymer nanocomposites of AESO $\mathbf{2}$ and $\mathbf{3}$ are termed polyAESO 2 and polyAESO 3, respectively.

\section{Characterisation of the gas-AESO liquid foams and macroporous polymer nanocomposites} Stability indices of gas-AESO liquid foams

The stability indices of gas-AESO liquid foams were assessed by monitoring the upward movement of the air-in-AESO boundary as a result of creaming at $20^{\circ} \mathrm{C}$. The movement of the air bubbles in AESO boundary was visually monitored every $24 \mathrm{~h}$. The stability index was 
calculated by taking the ratio between the creaming heights at the time of assessment and the initial height of the gas-AESO liquid foams.

\section{Structure and morphology of the macroporous polymer nanocomposites}

The internal structure and morphology of the macroporous polymers and nanocomposites were characterised using variable pressure scanning electron microscopy (SEM) (JSM 5610 LV, Jeol Ltd, Herts, UK) using an accelerating voltage of $10 \mathrm{kV}$. The macroporous polymer nanocomposites were cut using a scalpel into approximately $0.5 \mathrm{~cm}^{3}$ pieces and stuck onto aluminium SEM stubs using carbon tabs. Prior to SEM, the samples were Au coated (K550 sputter coater, Emitech Ltd, Ashford, Kent, UK) for 2 min at $20 \mathrm{~mA}$.

\section{Density and porosity of the macroporous polymer nanocomposites}

He pycnometry (AccuPyc 1330, Micromeritrics Ltd, Dunstable, UK) was used to measure the matrix (true) density of the polymer. Prior to this measurement, the polymer foams were crushed into powder using pesto and mortar. The envelope (foam) density of the cylindrical macroporous polymer was calculated by taking the ratio between the mass and the volume of the macroporous polymer, which was determined from the diameter and the height of the material. The porosities of the macroporous polymer nanocomposites were calculated as follows:

$$
P=\left(1-\frac{\rho_{e}}{\rho_{m}}\right) \times 100 \%
$$


Where $\mathrm{P}, \rho_{\mathrm{e}}$ and $\rho_{\mathrm{m}}$ are the porosity of the macroporous polymer, envelope (foam) density and matrix (true) density, respectively. A total of 5 specimens were measured for each type of sample.

\section{Thermal gravimetric analysis (TGA) of the macroporous polymer nanocomposites}

The degradation behaviour of the macroporous polymers and nanocomposites was characterised using TGA (TGA Q500, TA Instruments, UK). A piece of a sample with an approximate mass of $20 \mathrm{mg}$ was heated from room temperature to $800^{\circ} \mathrm{C}$ at a heating rate of $10^{\circ} \mathrm{C} \mathrm{min}{ }^{-1}$ in nitrogen atmosphere.

\section{Compression properties of the macroporous polymer nanocomposites}

The macroporous polymer nanocomposites were tested in compression using an Instron universal material testing machine (Instron 4505, Instron Corporation, MA, USA) equipped with a $1 \mathrm{kN}$ load cell. The test was conducted in accordance to BS ISO 844: 2009. The cylindrical test specimens had the same diameter and height of $25 \mathrm{~mm}$. Strain gauges (FLA-1-11, Techni Measure, Studley, UK) were glued onto the middle portion of the test specimens using cyanoacrylate glue (EVERBUILD Building Products Ltd, Leeds, UK). In order to avoid the flue filling the pores, only a very thin layer of glue was applied on the strain gauges. The samples were compressed between two flat and parallel thick polished plates coated with Teflon. Specimens were tested at a crosshead speed of $1 \mathrm{~mm} \mathrm{~min}^{-1}$. A total of 5 specimens were tested for each type of sample. The errors tabulated are standard deviations.

\section{Acknowledgements}


The authors would like to thank the UK Engineering and Physical Research Council (EPSRC) for funding KYL (EP/F032005/1), the Challenging Engineering Programme of the EPSRC for funding LCW and JJB (EP/E007538/1).

\section{References}

1. C. Forman, BCC Research, MA, USA, 2001.

2. V. O. Ikem, A. Menner and A. Bismarck, Langmuir, 2010, 26, 8836-8841.

3. R. C. Thomson, M. J. Yaszemski, J. M. Powers and A. G. Mikos, J. Biomater. Sci.Polym. Ed., 1995, 7, 23-38.

4. J. M. Karp, P. D. Dalton and M. S. Shoichet, MRS Bull., 2003, 28, 301-306.

5. L. Safinia, K. Wilson, A. Mantalaris and A. Bismarck, Macromol. Biosci., 2007, 7, $315-$ 327.

6. P. Ciambelli, V. Palma and E. Palo, Catal. Today, 2010, 155, 92-100.

7. A. Siriruk, Y. J. Weitsman and D. Penumadu, Compos. Sci. Technol., 2009, 69, 814-820.

8. J. W. Kang, J. M. Kim, M. S. Kim, Y. H. Kim, W. N. Kim, W. Jang and D. S. Shin, Macromol. Res., 2009, 17, 856-862.

9. L. J. Lee, C. C. Zeng, X. Cao, X. M. Han, J. Shen and G. J. Xu, Compos. Sci. Technol., 2005, 65, 2344-2363.

10. W. T. Zhai, S. N. Leung, L. Wang, H. E. Naguib and C. B. Park, J. Appl. Polym. Sci., 2010, 116, 1994-2004.

11. M. Mihai, M. A. Huneault, B. D. Favis and H. B. Li, Macromol. Biosci., 2007, 7, 907920.

12. D. J. Kim, S. W. Kim, H. J. Kang and K. H. Seo, J. Appl. Polym. Sci., 2001, 81, 24432454.

13. J. J. Blaker, V. Maquet, R. Jerome, A. R. Boccaccini and S. N. Nazhat, Acta Biomater., 2005, 1, 643-652.

14. H. Y. Ma, J. A. Hu and P. X. Ma, Adv. Funct. Mater., 2010, 20, 2833-2841.

15. M. Singh, B. Sandhu, A. Scurto, C. Berkland and M. S. Detamore, Acta Biomater., 2010, 6, 137-143.

16. I. Akartuna, E. Tervoort, J. C. H. Wong, A. R. Studart and L. J. Gauckler, Polymer, 2009, 50, 3645-3651.

17. A. Menner, K. Haibach, R. Powell and A. Bismarck, Polymer, 2006, 47, 7628-7635.

18. R. Murakami and A. Bismarck, Adv. Funct. Mater., 2010, 20, 732-737.

19. U. T. Gonzenbach, A. R. Studart, E. Tervoort and L. J. Gauckler, J. Am. Ceram. Soc., 2007, 90, 16-22.

20. L. Marlin, A. J. Durante and E. G. Schwarz, Journal of Cellular Plastics, 1975, 11, $317-$ 322.

21. R. W. Greer and G. L. Wilkes, J. Appl. Polym. Sci., 1996, 62, 1115-1128.

22. A. J. Brown, The Journal of Chemical Society Transactions, 1886, 49, 172-187.

23. W. Czaja, D. Romanovicz and R. M. Brown, Cellulose, 2004, 11, 403-411.

24. M. Iguchi, S. Yamanaka and A. Budhiono, J. Mater. Sci., 2000, 35, 261-270.

25. Y. C. Hsieh, H. Yano, M. Nogi and S. J. Eichhorn, Cellulose, 2008, 15, 507-513. 
26. J. J. Blaker, K. Y. Lee, X. X. Li, A. Menner and A. Bismarck, Green Chem., 2009, 11, 1321-1326.

27. M. Pommet, J. Juntaro, J. Y. Y. Heng, A. Mantalaris, A. F. Lee, K. Wilson, G. Kalinka, M. S. P. Shaffer and A. Bismarck, Biomacromolecules, 2008, 9, 1643-1651.

28. J. Juntaro, M. Pommet, G. Kalinka, A. Mantalaris, M. S. P. Shaffer and A. Bismarck, Adv. Mater., 2008, 20, 3122-3126.

29. S. P. Wu, M. Z. Rong, M. Q. Zhang, J. Hu and T. Czigany, J. Biobased Mater. Bioenergy, 2007, 1, 417-426.

30. L. M. Bonnaillie and R. P. Wool, J. Appl. Polym. Sci., 2007, 105, 1042-1052.

31. A. Okiyama, M. Motoki and S. Yamanaka, Food Hydrocolloids, 1993, 6, 493-501.

32. D. K. Sarker, D. Bertrand, Y. Chtioui and Y. Popineau, J. Texture Stud., 1998, 29, 15-42.

33. P. Walstra, in Foams: Physics, chemistry and structure, ed. A. J. Wilson, Springer-Verlag Berlin, York, 1989, pp. 1-16.

34. F. Carn, A. Colin, O. Pitois, M. Vignes-Adler and R. Backov, Langmuir, 2009, 25, 78477856.

35. D. Behera and A. K. Banthia, J. Appl. Polym. Sci., 2008, 109, 2583-2590.

36. S. Grishchuk and J. Karger-Kocsis, Express Polym. Lett., 2011, 5, 2-11.

37. A. K. O'Brien and C. N. Bowman, Macromolecules, 2006, 39, 2501-2506.

38. N. C. Hilyard and J. Young, in Mechanics of Cellular Plastics, ed. N. C. Hilyard, Applied Science Publisher Ltd, Essex, 1982, pp. 1-26.

39. K. Y. Lee, F. Quero, J. J. Blaker, C. A. S. Hill, S. J. Eichhorn and A. Bismarck, Cellulose, 2011, 18, 595-605.

40. K. Y. Lee, J. J. Blaker and A. Bismarck, Compos. Sci. Technol., 2009, 69, 2724-2733. 


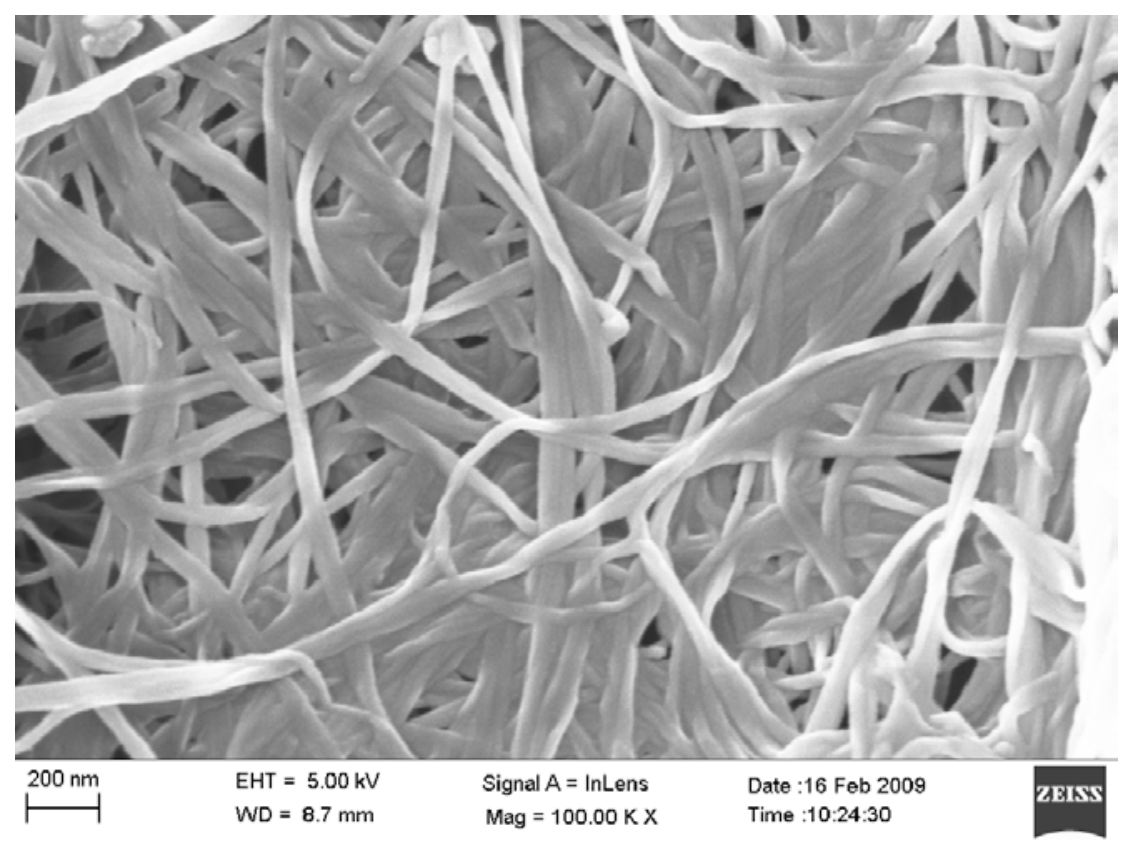

Figure 1. Scanning electron micrographs of bacterial cellulose nanofibrils. Adapted from reference 40 with permission from Elsevier.

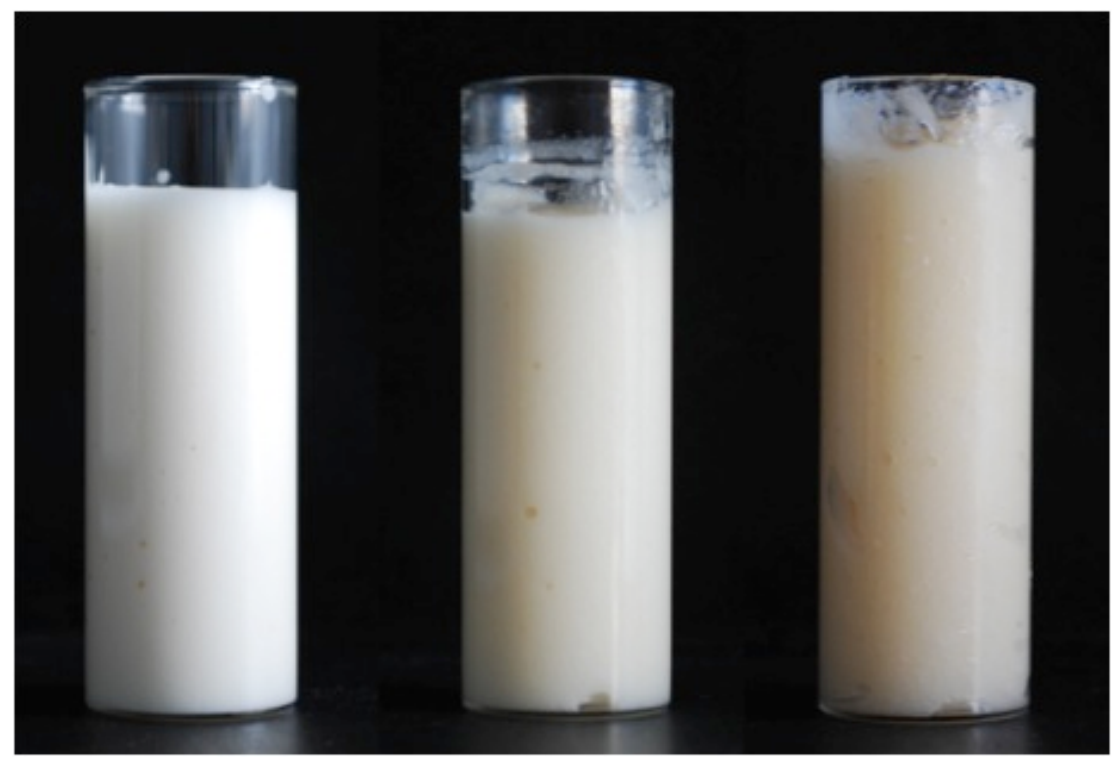

Figure 2. A photograph showing the gas-monomer liquid foam 5 min after mechanical frothing. Left: AESO 1 (0 wt.$\%$ BC), middle: AESO 2 (0.5 wt.-\% BC) and right: AESO 3 (1 wt.- $\%$ BC). 


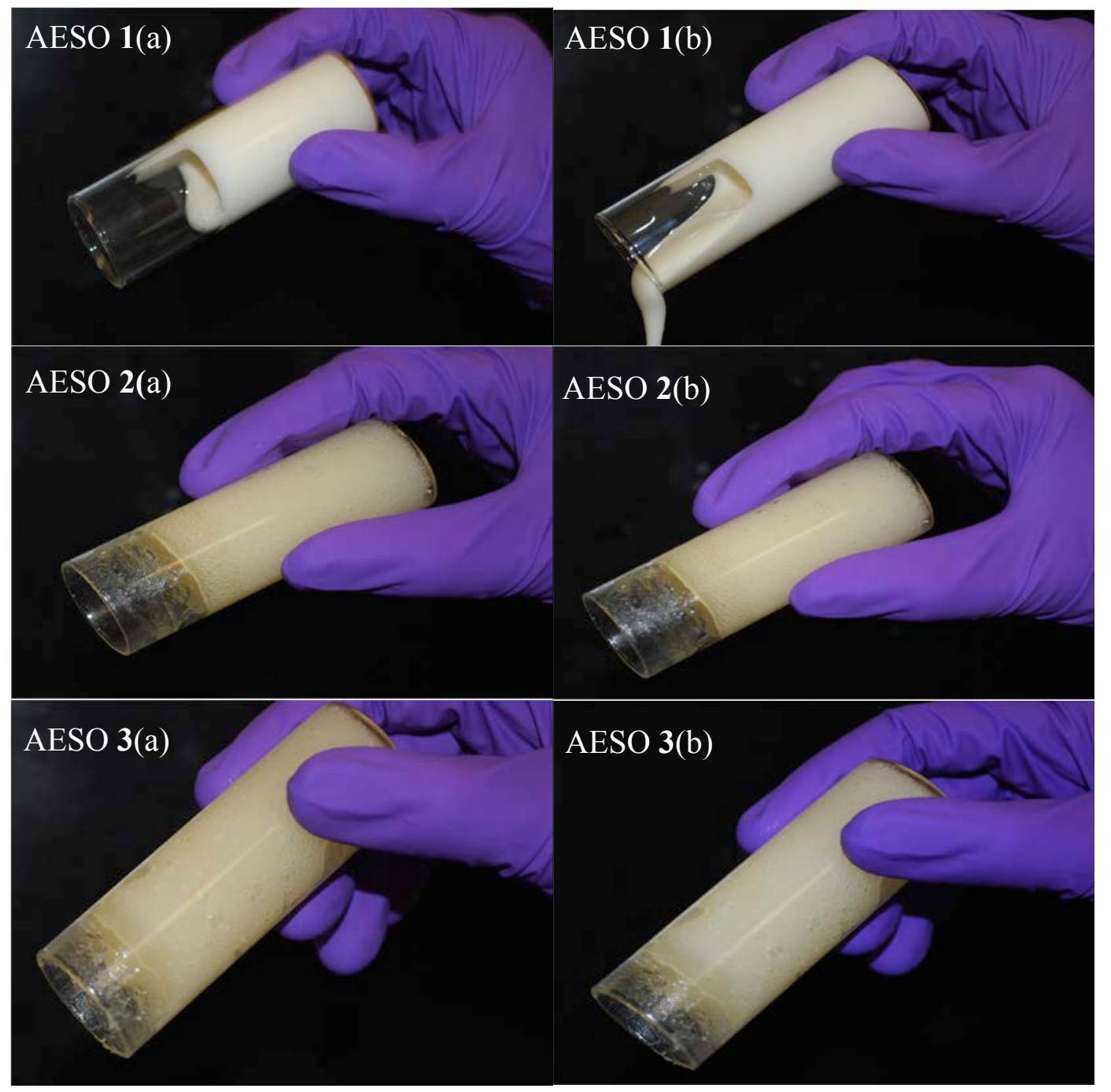

Figure 3. Images showing the capability of the gas-monomer liquid foam to flow. (a) Photographs taken after immediately $(0 \mathrm{~min})$ and (b) photographs taken $1 \mathrm{~min}$ after the liquid foam was tilted to this angle. 


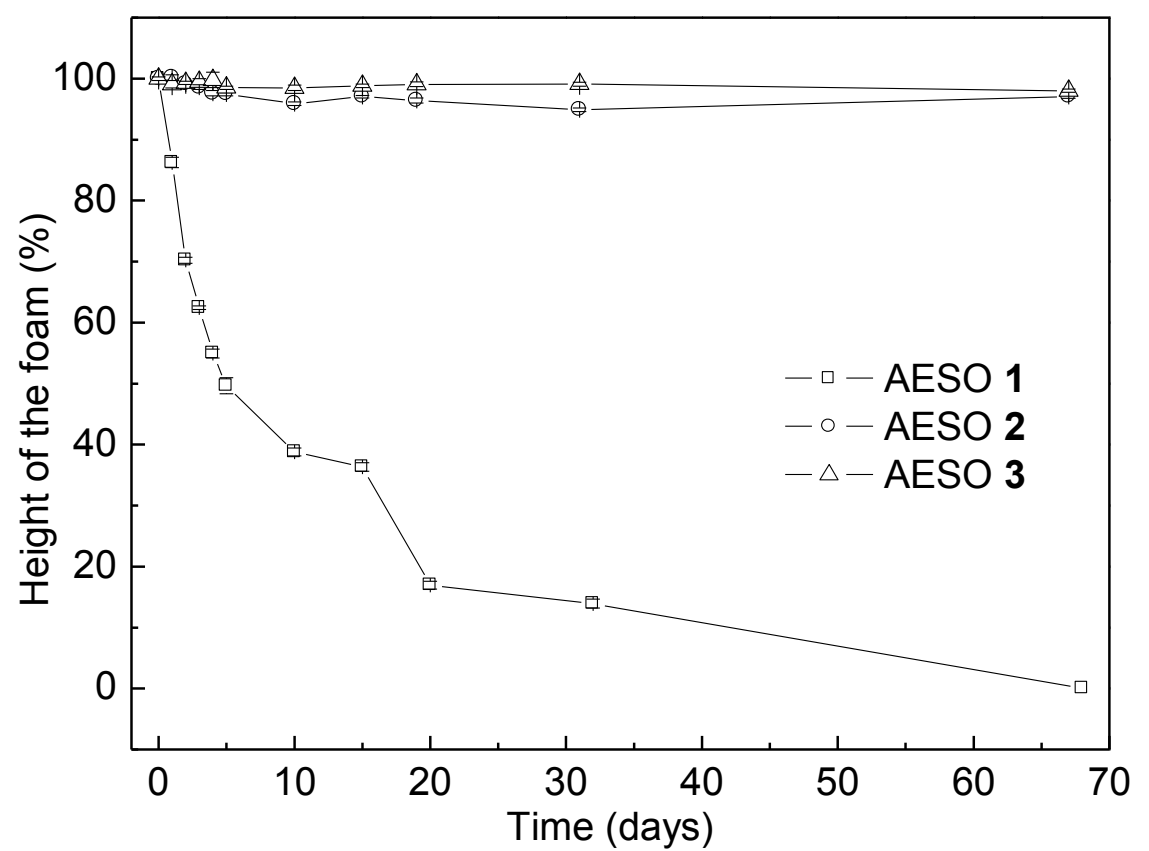

Figure 4. The stability index of the mechanically frothed gas-monomer liquid foams. AESO 1: 0 wt.-\% BC, AESO 2: 0.5 wt.-\% BC and AESO 3: 1 wt.-\% BC. 


\section{Top View}

Side View
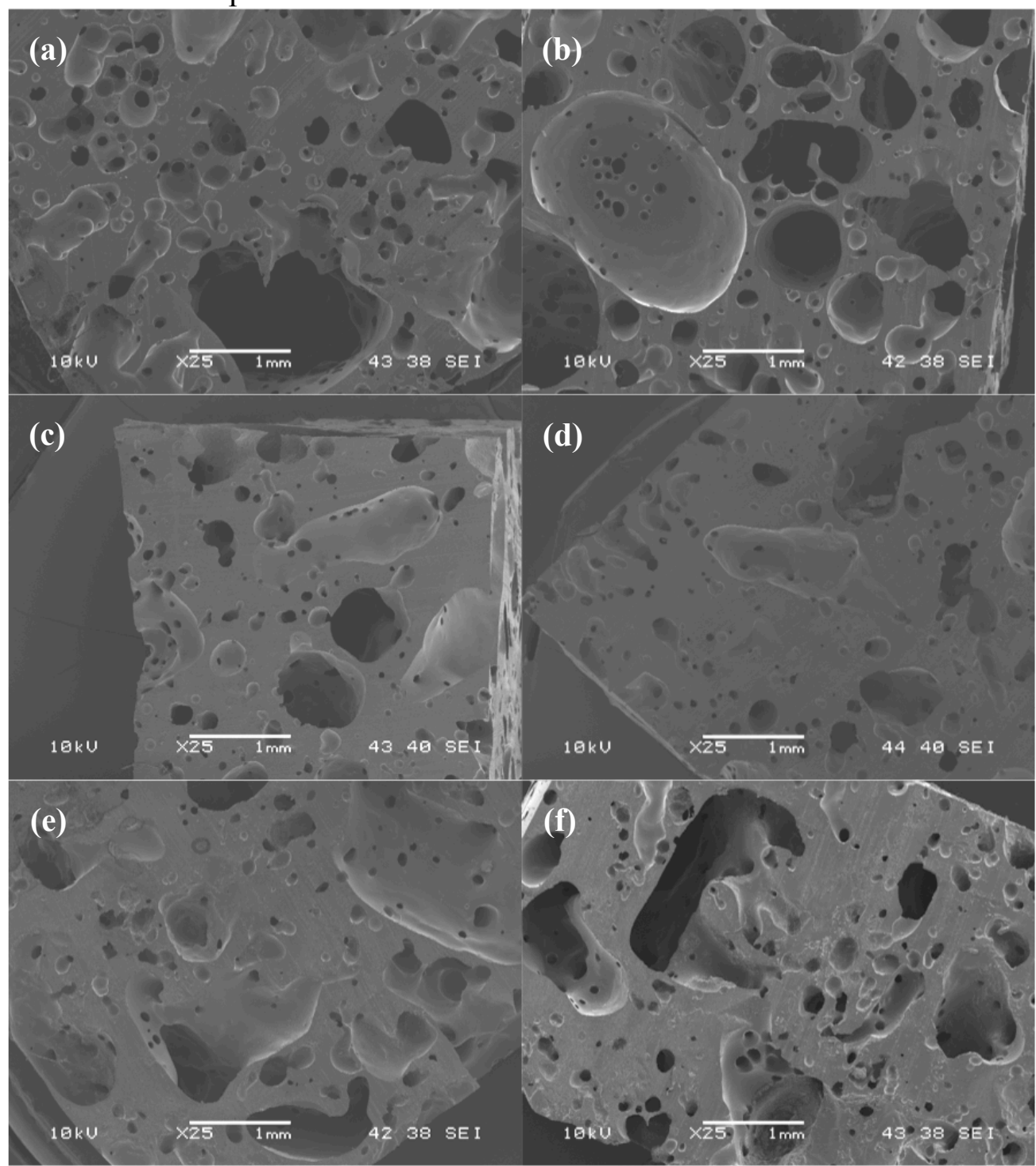

Figure 5. SEM images of the polyAESO. (a) and (b) are polyAESO 1 ( $0 \mathrm{wt.} . \% \mathrm{BC})$, (c) and (d) are polyAESO 2 $(0.5 \mathrm{wt} .-\% \mathrm{BC}),(\mathrm{e})$ and $(\mathrm{f})$ are polyAESO 3 (1 wt.- $\% \mathrm{BC})$. 


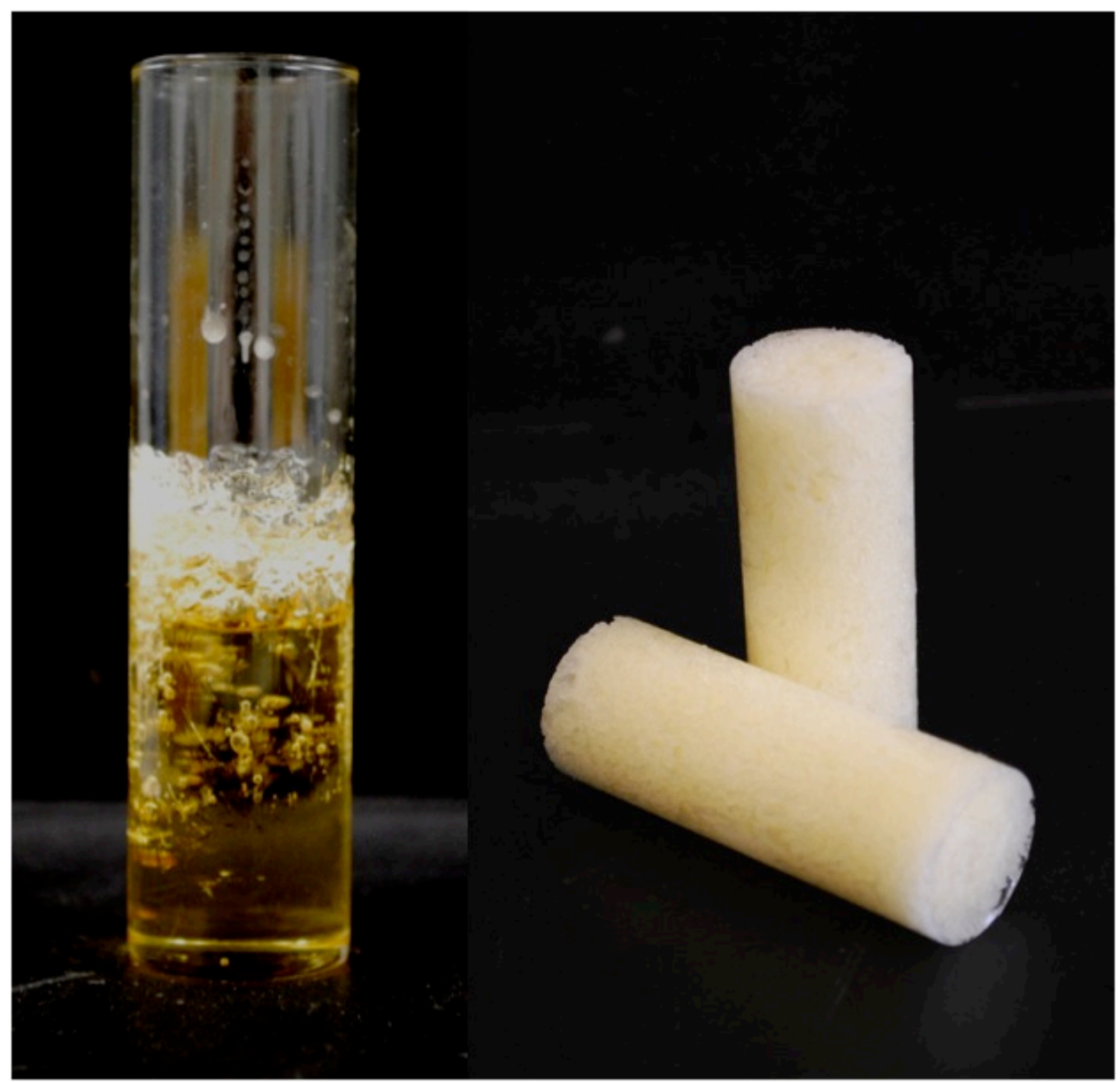

Figure 6: A comparison between non-mechanically frothed and air templated polyAESO. The photograph on the left shows polyAESO that was not mechanically frothed prior to its polymerization and the image on the right shows the air templated polyAESO 1 ( 0 wt.- $\%$ BC). 


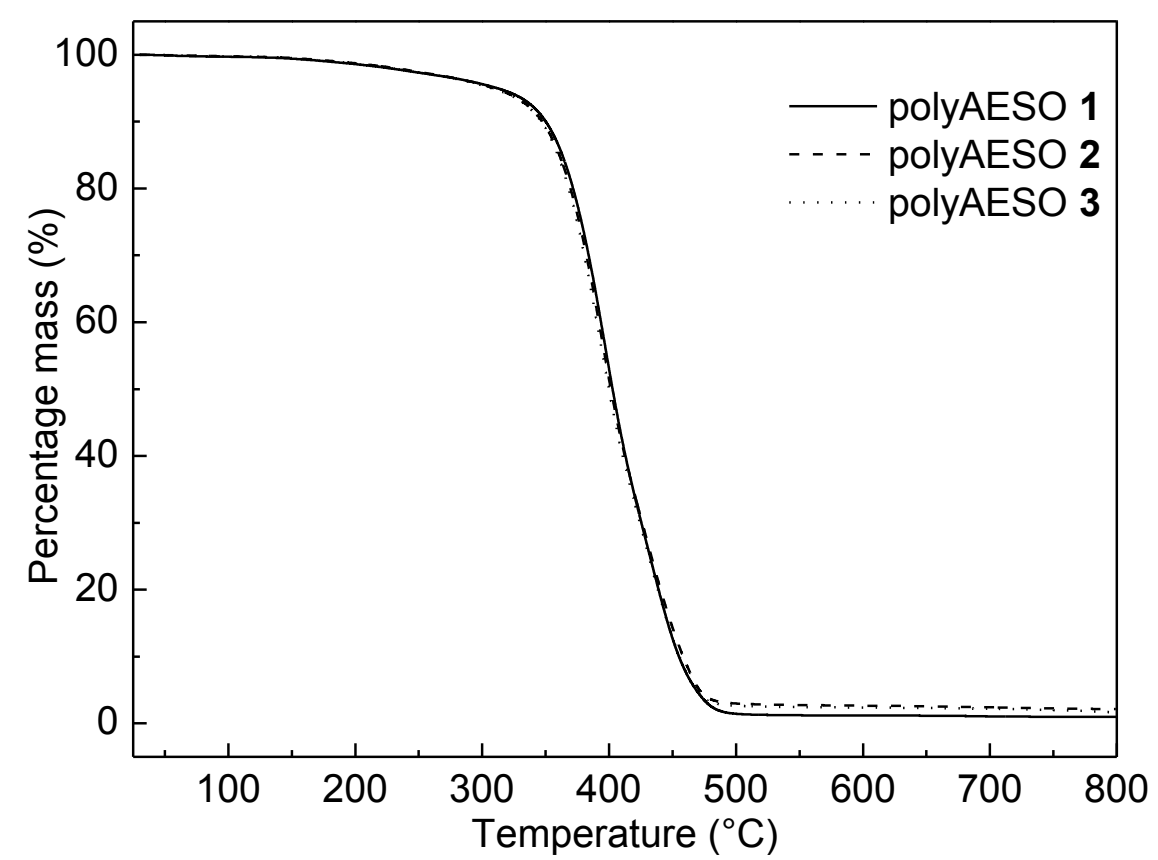

Figure 7. The thermal degradation behaviour of the macroporous polymer nanocomposites.

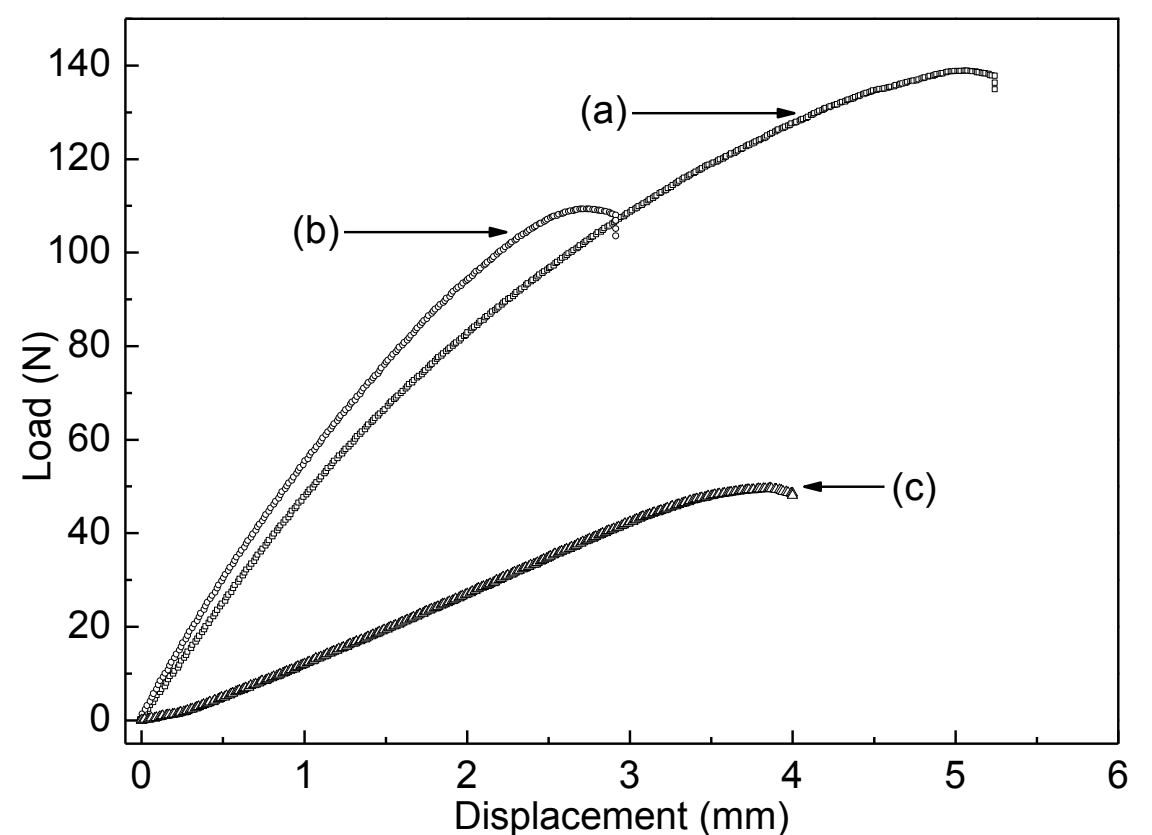

Figure 8: Characteristic load-displacement curves of the macroporous polymers. (a) polyAESO 1 (0 wt.-\% BC), (b) polyAESO 2 (0.5 wt.-\% BC) and (c) polyAESO 3 (1 wt.-\% BC). 
Table 1 . The envelope density, matrix density and porosity of the macroporous polymers. $\rho_{\mathrm{e}}, \rho_{\mathrm{m}}$ and $\mathrm{P}$ correspond to the envelope density, matrix density and porosity of the macroporous polymers, respectively. The errors tabulated are the standard errors.

\begin{tabular}{llll}
\hline Sample & $\rho_{\mathrm{e}}\left(\mathrm{g} \mathrm{cm}^{-3}\right)$ & $\boldsymbol{\rho}_{\mathrm{m}}\left(\mathrm{g} \mathrm{cm}^{-3}\right)$ & $\mathbf{P ~ ( \% )}$ \\
\hline polyAESO 1 (0 wt.-\% BC) & $0.44 \pm 0.01$ & $1.07 \pm 0.01$ & $59 \pm 1$ \\
polyAESO 2 (0.5 wt.-\% BC) & $0.49 \pm 0.01$ & $1.08 \pm 0.01$ & $54 \pm 1$ \\
polyAESO 3 (1 wt.-\% BC) & $0.58 \pm 0.01$ & $1.08 \pm 0.01$ & $45 \pm 1$ \\
\hline
\end{tabular}

Table 2. Mechanical properties of the macroporous polymer. $E_{c}, \sigma_{c}, E_{c}$ ' and $\sigma_{c}$ ' denote compression modulus, compression strength, specific compression modulus and specific compression strength, respectively. The errors tabulated are the standard errors.

\begin{tabular}{|c|c|c|c|c|}
\hline Sample & $\mathbf{E}_{\mathrm{c}}(\mathrm{MPa})$ & $\sigma_{c}(\mathbf{k P a})$ & $\begin{array}{l}\mathbf{E}_{\mathrm{c}}, \\
\left(\mathrm{MPa} \mathrm{kg}{ }^{-1} \mathrm{~m}^{3}\right)\end{array}$ & $\begin{array}{l}\sigma_{\mathrm{c}}^{\prime} \\
\left(\mathrm{kPa} \mathrm{kg}^{-1} \mathrm{~m}^{3}\right)\end{array}$ \\
\hline polyAESO 1 (0 wt.-\% BC) & $111 \pm 11$ & $343 \pm 34$ & $253 \pm 25$ & $779 \pm 79$ \\
\hline polyAESO 2 ( 0.5 wt.- $\%$ BC) & $166 \pm 33$ & $254 \pm 19$ & $338 \pm 68$ & $519 \pm 39$ \\
\hline polyAESO 3 (1 wt.-\% BC) & $52 \pm 9$ & $183 \pm 26$ & $90 \pm 15$ & $315 \pm 46$ \\
\hline
\end{tabular}


Graphics for the Abstract

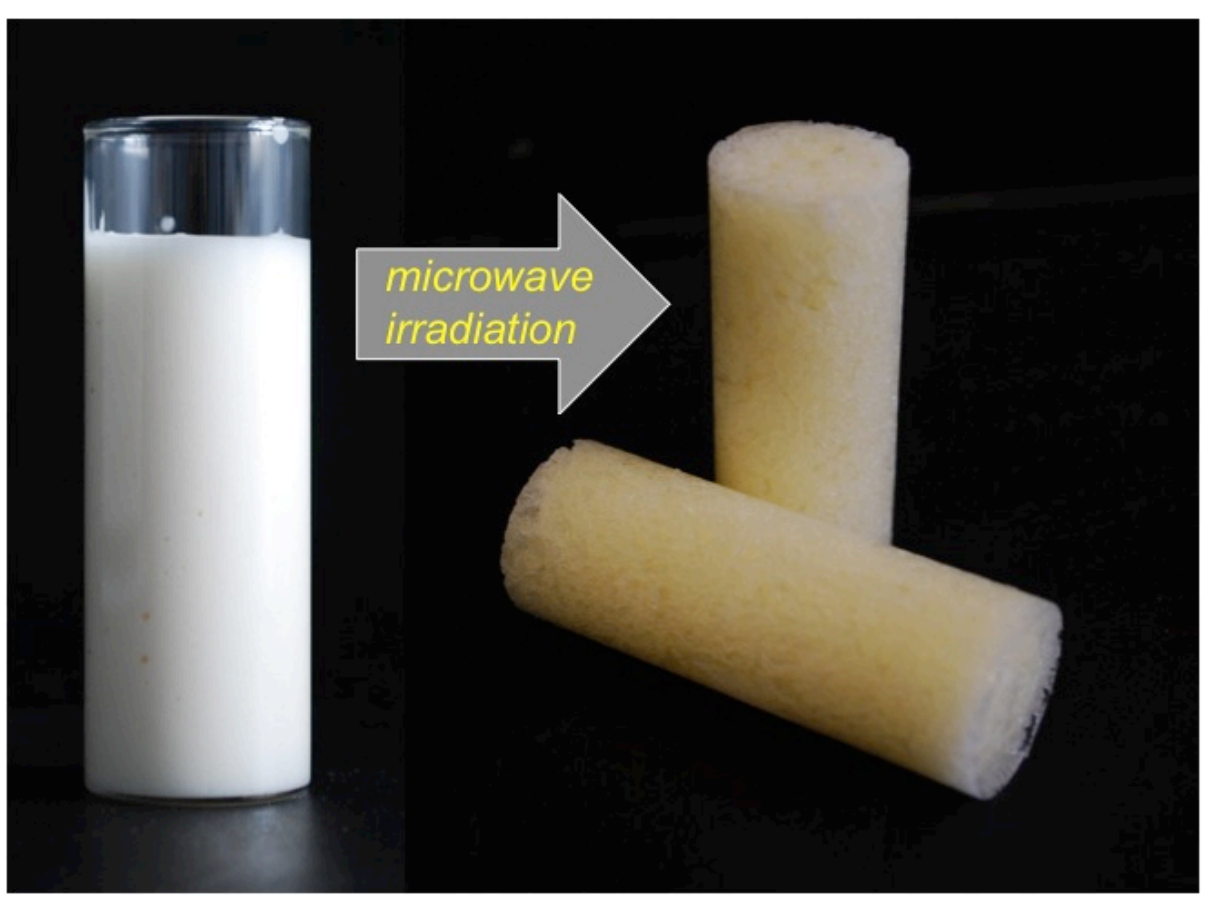




\section{The TOC entry}

Bio-based bacterial cellulose (BC) reinforced polyAESO nanocomposite foams were prepared by mechanical frothing of acrylated epoxidised soybean oil (AESO) followed by microwave heating initiated polymerisation. The introduction of $\mathrm{BC}$ significantly enhanced the stability of the gas-AESO foam templates. The compression modulus of the macroporous polymer nanocomposites was found to increase with low $\mathrm{BC}$ content.

The TOC figure

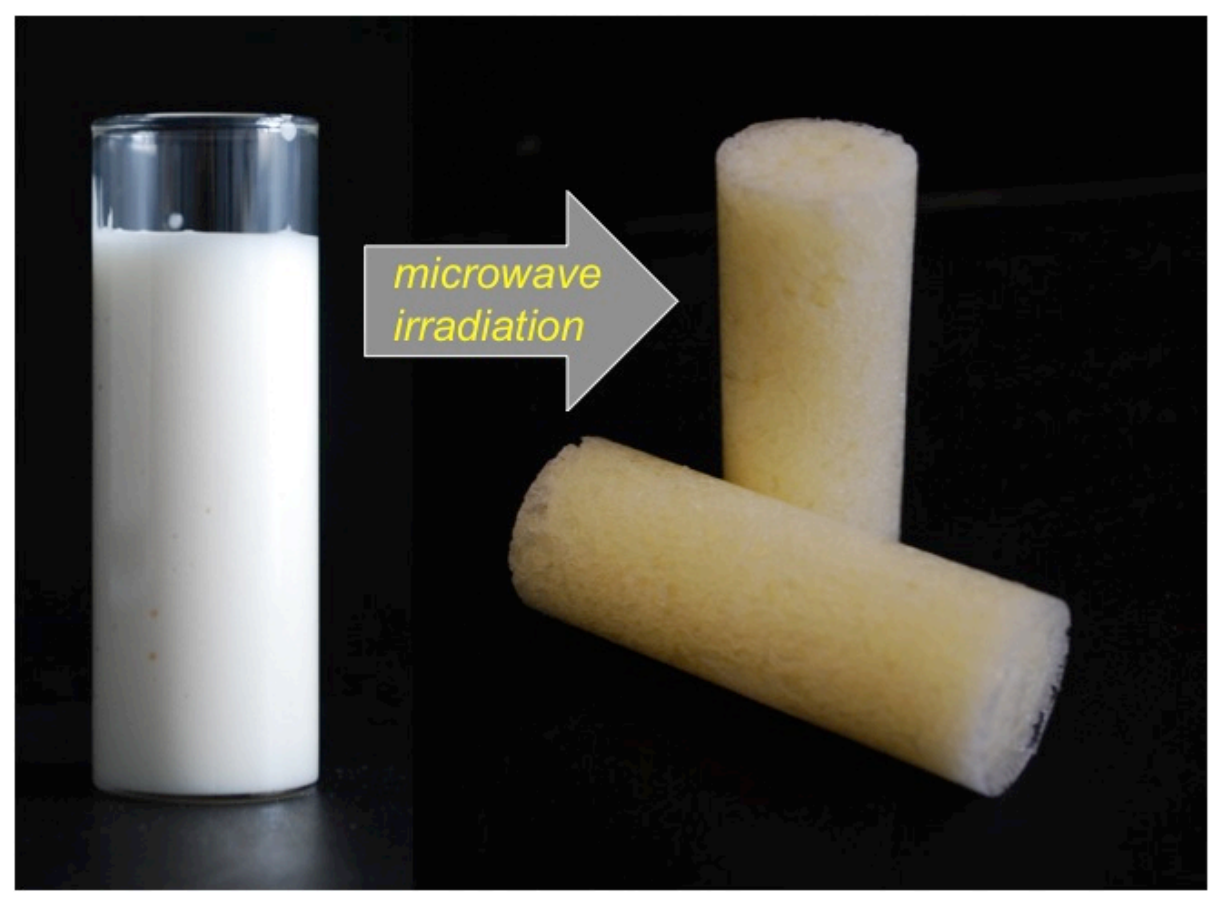

